\title{
Cutting Parameter Optimization in Finishing Milling of Ti-6Al-4V Titanium Alloy under MQL Condition using TOPSIS and ANOVA Analysis
}

\author{
Van Canh Nguyen \\ Department of Manufacturing Technology \\ Faculty of Mechanical Engineering \\ Hanoi University of Industry \\ Hanoi, Vietnam \\ nguyenvancanh@haui.edu.vn
}

\author{
Thuy Duong Nguyen \\ Department of Machine Tool and Tribology \\ School of Mechanical Engineering \\ Hanoi University of Science and Technology \\ Hanoi, Vietnam \\ duong.nguyenthuy@hust.edu.vn
}

\author{
Dung Hoang Tien \\ Department of Manufacturing Technology \\ Faculty of Mechanical Engineering \\ Hanoi University of Industry \\ Hanoi, Vietnam \\ tiendung@haui.edu
}

\begin{abstract}
Titanium and its alloys give immense specific strength, imparting properties such as corrosion and fracture resistance, making them the right candidate for medical and aerospace applications. There is a wide range of engineering applications that use titanium alloys in a variety of forms. The cost of these alloys is slightly higher in comparison to other variants due to the problematic extraction of the molten process. To reduce costs, titanium alloy products could be made by casting, isothermal forging, radial swaging, or powder metallurgy, although these techniques require some kind of finishing machining process. Titanium and its alloys are difficult to machine due to skinny chips leading to a small cutting tool-workpiece contact area. The thermal conductivity of titanium alloys is too low and the stress produced is too large due to the small contact area, which results in very high cutting temperatures. This paper deals with the experimental study of the influence of the Minimum Quantity Lubricant (MQL) environ ment in the milling of Ti-6Al-4V alloy considering the optimization of surface roughness and production rate. Taguchi-based TOPSIS and ANOVA were used to analyze the results. The experimental results show that MQL with vegetable oil is successfully applied in the milling of Ti-6Al-4V. The research confirms the suitability of TOPSIS in solving the Multiple Criteria Decision Making (MCDM) issue, by choosing the best alternative at $V_{c}=120 \mathrm{~m} / \mathrm{min}, f_{z}=0.065 \mathrm{~mm} / \mathrm{tooth}$, and $a_{p}=0.2 \mathrm{~mm}$, where the surface roughness and material removal rate are $0.41 \mu \mathrm{m}$ and $44.1492 \mathrm{~cm}^{3} / \mathrm{min}$ respectively. Besides, ANOVA can be used to predict the best parameters set in the milling process based on the regression model. The parameters predicted by ANOVA analysis do not coincide with any implemented parameters.
\end{abstract}

Keywords-surface milling; surface roughness; Taguchi-based TOPSIS; titalium alloy; Ti-6Al-4V; MCDM; MQL

\section{INTRODUCTION}

According to the thermophysical properties at elevated temperatures, titanium alloy $\mathrm{Ti}-6 \mathrm{Al}-4 \mathrm{~V}$ is considered as the best material to manufacture parts in medical or euro space industry $[1,2]$. However, machining Ti-6Al-4V is complicated because the temperature is usually very high in the contact area between the workpiece and the cutting tool [3-9]. To reduce cutting heat, Metalworking Fluids (MWFs) have been selected as the most common solution [10]. Due to the harmful effects of WMF to the operator's health and environment, reducing MWF consumption is always considered. In this aspect, dry machining and Minimum Quantity Lubricant (MQL) are two of the most effective alternatives. For the past 20 years, many publications have confirmed the effectiveness of using MQL metalworking in general and Ti-6Al-4V machining in particular. Authors in [11] researched the role of MQL condition in tool wear and surface quality in turning process with an uncoated cutting tool. The research showed the encouraging results where the MQL environment leads to the significant reducing of tool wear and surface roughness mainly through the declining of the temperature in cutting area and the change of the interaction between chip-tool and tool-workpiece during machining. Authors in [12] studied the grinding of Ti$6 \mathrm{Al}-4 \mathrm{~V}$ titanium alloy and the effects of different lubrication conditions on the surface quality. The research showed that vegetable oil can be applied in the milling of titanium alloys under MQL conditions. Hence, the MQL technique was applied in this study work to replace conventional lubricants in the milling process.

Corresponding author: Thuy Duong Nguyen 
Authors in [13] carried out a study research to apply a Multiple Criteria Decision Making (MCDM) approach for enhancing University accreditation process. The results showed that MCDM is suitable to solve multi response optimization problems. Taguchi-based techniques, namely TOPSIS, MOORA, VIKOR, COPRAS, etc. have been often used to solve MCDM problems with high accuracy. Authors in $[13,14]$ used the TOPSIS method to solve the MCDM problem. These researches show that TOPSIS could be applied to find the best alternative easily and quickly. The problem here is that the TOPSIS or other Taguchi-based technique can help finding the best solutions from the conducted experiments only. This means that this method cannot help predicting or finding the exact optimum parameters set. To come over this disadvantage, new methods can be applied, for example Genetic Algorihm or combinations of some of the conventional methods. Authors in [7] used statistical and soft computing techniques to determine the optimum surface roughness in the milling of Ti-6Al-4V. Their results show that the RSM model could be applied in predicting the optimum surface roughness value in the milling of titanium alloys. However, the predictive result given by Artificial Neural Networks (ANNs) is more accurate than by the Response Surface Method (RSM).

Authors in [15] applied an experimental model to optimize and predict the effect of the cutting tool on surface roughness and geometrical characteristics in the drilling of $\mathrm{H} 13$ steel. The Evolutionary Multiple Attribute Optimization algorithm was employed to find the optimum parameters set. NSGA-II (Nondominated Sorting Genetic Algorithm) method was developed, and the regression functions were considered to find the optimum of surface roughness. The successful optimization results are consistent with the experimental findings, and ultimately the optimal set of cutting parameters can be chosen by machining operators according to the application. The study also showed that increased cutting speed and liquid coolant intensity decline surface quality. By contrast, the rising of cutting depth, tool diameter, and feed rate led to better surface quality. Many other studies showed that MQL and vegetable oil are suitable for machining titanium alloy surfaces. The machining of titanium alloys is a major research topic. The challenge is mainly the cost, due to the very high price of the material and the cutting tools leading usually to a reduced number of experiments. In this case, using the Taguchi design method of an experiment is addressed as one of the best solutions [16]. The Technique for Order Preference by Similarity to Ideal Solution (TOPSIS) effectively identifies the best alternative quickly. Authors in [17] succeeded in applying an MCDM model to find the optimum shot-peening parameters set. Authors in [18] were successful in multi-objective optimization on surface quality optimization and MRR in the face milling of AISI 304 steel. The results show that a significant influence of all milling parameters on the MRR and both the feed-rate and the depth of cut have a significant effect on the cutting force. In the current work, information entropy is performed to derive the objective weights of the evaluation criteria. An entropy-based TOPSIS is employed to rank the alternatives in order of preference and then choose the best solution that conforms to the decision maker's idea $[19,21]$

\section{RESEARCH METHODOLOGY}

\section{A. Optimization Issues}

Surface roughness and production rate are two standard and essential criteria that must be considered in machining. Improving surface quality leads to reduced Material Removal Rate (MRR). So, finding the best solution to balance surface roughness and production rate is a critical issue. In this study, two primary responses, including the arithmetical mean roughness $\left(R_{a}\right)$ and specific Material Removal Rate (MRR), are optimized simultaneously using the entropy-based TOPSIS model. The average roughness value is calculated as:

$$
R_{a}=\frac{R_{a 1}+R_{a 2}+R_{a 3}+R_{a 4}+R_{a 5}}{5}
$$

where $R_{a i}$ is the arithmetic roughness at the $i$-th position.

The production rate is the amount of material removed per time unit and is determined by:

$$
\operatorname{MRR}=\frac{w \cdot a_{p} \cdot v_{f}}{1000}
$$

where MRR is the production rate in $\mathrm{cm}^{3} / \mathrm{min}, a_{p}$ is the depth of cut in mm, $w$ is the width of cut in $\mathrm{mm}$, and $v_{f}$ is feed speed in $\mathrm{m} / \mathrm{min}$.

For the milling process, the cutting parameters, including cutting speed $\left(V_{c}\right)$, depth of cut $\left(a_{p}\right)$, and feed rate $\left(v_{f}\right)$ can be considered as inputs. The values of cutting parameters are chosen by the suggestions of the cutting tool's manufacturer and the recommendations of any mold manufacturers. The variance factor data are shown in Table I. In this study, the MQL is fixed at $150 \mathrm{ml} / \mathrm{h}$ flow rate and $2 \mathrm{MPa}$ air pressure. The experiment is performed in 5-axis CNC Machine DMG DMU50 (Germany), and the surface roughness results were measured with the Mitutoyo Surftest JS-310 (Japan).

TABLE I. THE VALUE SET OF CUTTING PARAMETERS

\begin{tabular}{|c|c|c|c|c|c|c|}
\hline \multirow{2}{*}{ No. } & \multirow{2}{*}{ Param eter } & \multirow{2}{*}{ Symbol } & \multirow{2}{*}{ Unit } & \multicolumn{3}{|c|}{ Level } \\
\cline { 5 - 7 } & & & & $\mathbf{- 1}$ & $\mathbf{0}$ & $\mathbf{1}$ \\
\hline 1 & Cutting Speed & $V_{c}$ & $\mathrm{~m} / \mathrm{min}$ & 120 & 210 & 300 \\
\hline 2 & Feed & $f_{z}$ & $\mathrm{~mm} /$ tooth & 0.02 & 0.06 & 0.10 \\
\hline 3 & Depth of cut & $a_{p}$ & $\mathrm{~mm}$ & 0.1 & 0.5 & 0.9 \\
\hline
\end{tabular}

The optimizing issue is described below. The study's approach uses the MCMD method for selecting the best solution for minimizing surface arithmetic roughness $\left(R_{a}\right)$ and maximizing the production rate (MRR).

TABLE II. EXPERIMENTAL DATA

\begin{tabular}{|l|l|l|l|l|l|}
\hline Run & $\boldsymbol{V}_{\boldsymbol{c}}$ & \multicolumn{1}{|c|}{$\boldsymbol{f}_{\boldsymbol{z}}$} & $\boldsymbol{a}_{\boldsymbol{p}}$ & \multicolumn{1}{|c|}{$\boldsymbol{R}_{\boldsymbol{a}}$} & MRR \\
\hline 1 & 60 & 0.03 & 0.2 & 0.281 & 5.42 \\
\hline 2 & 60 & 0.065 & 0.4 & 0.336667 & 1.08 \\
\hline 3 & 60 & 0.1 & 0.6 & 0.737333 & 16.25 \\
\hline 4 & 90 & 0.03 & 0.4 & 0.328 & 21.67 \\
\hline 5 & 90 & 0.065 & 0.6 & 0.321333 & 10.83 \\
\hline 6 & 90 & 0.1 & 0.2 & 0.506667 & 2.17 \\
\hline 7 & 120 & 0.03 & 0.6 & 0.358667 & 32.5 \\
\hline 8 & 120 & 0.065 & 0.2 & 0.411667 & 43.33 \\
\hline 9 & 120 & 0.1 & 0.4 & 0.635667 & 16.25 \\
\hline
\end{tabular}




\section{B. Multi-Response Optimization Framework}

The TOPSIS method was presented in [22, 23], and its steps are:

Step 1: Given a set of alternatives, $A=\left\{A_{i} \mid i=1,2, . . n\right\}$, and a set of criteria, $C=\left\{C_{j} \mid j=1,2, \ldots m\right\}$, where $X=\left\{x_{i j} \mid i=1,2, . . n, j=1,2, \ldots m\right\}$ denotes the set of performance ratings and $w=\left\{w_{j} \mid j=1,2, \ldots m\right\}$ is the set of weights. The information table $I=(A, C, X, W)$ can be represented as shown in Table III.

\section{TABLE III. THE INFORMATION TABLE OF TOPSIS}

\begin{tabular}{|c|c|c|c|c|}
\hline Alternative & $C_{1}$ & $C_{2}$ & $\ldots$ & $C_{m}$ \\
\hline$A_{1}$ & $x_{11}$ & $x_{12}$ & $\ldots$ & $x_{1 m}$ \\
\hline$A_{2}$ & $x_{21}$ & $x_{22}$ & $\ldots$ & \\
\hline$\vdots$ & $\vdots$ & & $\vdots$ & $\vdots$ \\
\hline$A_{n}$ & $x_{n 1}$ & $x_{n 2}$ & $\ldots$ & $x_{n m}$ \\
\hline$W$ & $w_{1}$ & $w_{2}$ & $\ldots$ & $w_{m}$ \\
\hline
\end{tabular}
28]

Step 2: Calculating the normalized rating by $[20,21,24-$

$$
r_{i j}=\frac{x_{i j}}{\sqrt{\sum_{i=1}^{m}\left(x_{i j}^{2}\right)}}, i=1,2 \ldots m ; j=1,2 \ldots n
$$

Step 3: Calculating the weighted normalized rating by:

$$
v_{i j}(x)=w_{j} r_{i j}(x), i=1,2 \ldots n ; j=1,2 \ldots m
$$

Step 4: Calculating a positive ideal point (PIS) and a negative ideal point (NIS) by:

$$
\begin{gathered}
\mathrm{PIS}=A^{+}=\left\{v_{1}^{+}(x), v_{2}^{+}(x), \ldots, v_{m}^{+}(x)\right\}=\left\{\left(\max _{i} v_{i j}(x) \mid j \in\right.\right. \\
\left.\left.J_{1}\right),\left(\min _{i} v_{i j}(x) \mid j \in J_{2}\right) \mid i=1,2 \ldots n\right\} \quad(5) \\
\mathrm{NIS}=A^{-}=\left\{v_{1}^{-}(x), v_{2}^{-}(x), \ldots, v_{m}^{-}(x)\right\}=\left\{\left(\min _{i} v_{i j}(x) \mid j \in\right.\right. \\
\left.\left.J_{1}\right),\left(\max _{i} v_{i j}(x) \mid j \in J_{2}\right) \mid i=1,2 \ldots n\right\} \quad \text { (6) }
\end{gathered}
$$

where $J_{1}$ and $J_{2}$ are the benefit and non-benefit criteria respectively.

Step 5: Calculating the separation from the PIS and the NIS among alternatives using the Euclidean distance, which is given as:

$$
\begin{aligned}
& D_{i}^{*}=\sqrt{\sum_{j=1}^{m}\left[v_{i j}(x)-v_{j}^{+}(x)\right]^{2}}, \quad i=1,2, \ldots n \\
& D_{i}^{-}=\sqrt{\sum_{j=1}^{m}\left[v_{i j}(x)-v_{j}^{-}(x)\right]^{2}}, \quad i=1,2, \ldots n
\end{aligned}
$$

Step 6: Determining the similarities to the PIS by the formula:

$$
C_{i}^{*}=\frac{D_{i}^{-}}{\left(D_{i}^{*}+D_{i}^{-}\right)}, i=1,2, \ldots n
$$

where $C_{i}^{*} \in[0,1] \forall i=1,2, \ldots n$.

Step 7: Arranging PIS $\left(C_{i}^{*}\right)$ and choosing the best and the worst alternatives according to their ranking. In this study, the weight set in (4) would be replaced by a new set, which is determined by entropy, given as in the following step.

Step 8: Calculating the entropy by:

$$
e_{j}=-\frac{1}{\ln (m)} \sum_{i=1}^{m}\left[r_{i j} \cdot \ln \left(r_{i j}\right)\right], i=1,2, \ldots m ; j=1,2, \ldots n
$$

Then the objective weight for each criterion can be determined as:

$$
w_{j}=\left[\frac{1-e_{j}}{\sum_{j=1}^{n}\left(1-e_{j}\right)}\right], j=1,2, \ldots n
$$

\section{EXPERIMENTAL PROCEDURE}

In this work, the titanium alloy Ti-6Al-4V is selected, and the five-axis milling center DMG DMU50 is used for the machining experiment. The experimental workpiece and machine are shown in Figures 1 and 2. The surface roughness value was measured 3 times at 3 different positions for each experiment by a Mitutoyo Surftest JS-310. The average value is shown in Table IV.
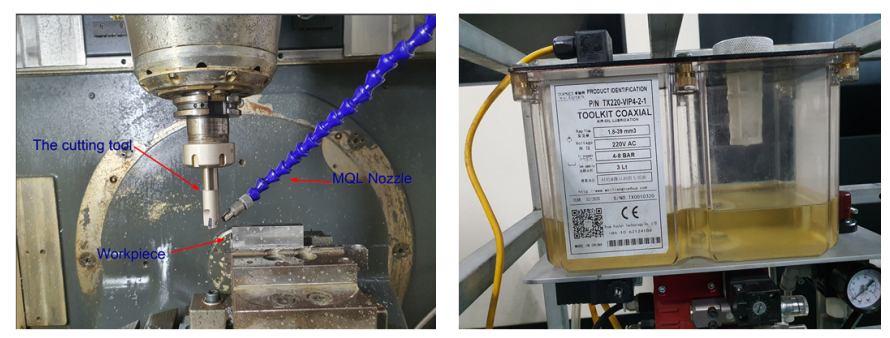

Fig. 1. Experimental set-up.

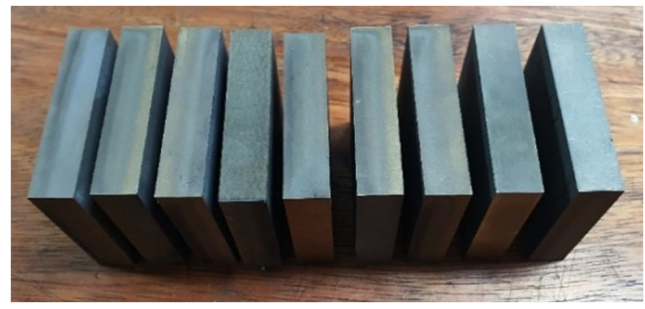

Fig. 2. Workpiece specimen.

IV. RESULTS AND DISCUSSION

\section{A. Optimization using Entropy-based TOPSIS}

Step 1: The given selected responses are arranged in the information table of TOPSIS according to Table IV.

TABLE IV. TOPSIS EXPERIMENTAL INFORMATION

\begin{tabular}{|c|c|c|}
\hline Alternative & $\boldsymbol{R}_{\boldsymbol{a}}$ & MRR \\
\hline$A_{1}$ & 0.281 & 5.42 \\
\hline$A_{2}$ & 0.336667 & 1.08 \\
\hline$A_{3}$ & 0.737333 & 16.25 \\
\hline$A_{4}$ & 0.328 & 21.67 \\
\hline$A_{5}$ & 0.321333 & 10.83 \\
\hline$A_{6}$ & 0.506667 & 2.17 \\
\hline$A_{7}$ & 0.358667 & 32.5 \\
\hline$A_{8}$ & 0.411667 & 43.33 \\
\hline$A_{9}$ & 0.635667 & 16.25 \\
\hline
\end{tabular}

Step 2: The given responses are transformed to nondimensional form by (3). The result is presented in Table V.

Step 3: The weigh set is calculated using entropy by (10) and (11). The summarized results are shown in Table VI. 
TABLE V. THE NON-DIMENSIONAL FORM

\begin{tabular}{|c|c|c|}
\hline \multirow{2}{*}{ Alternative } & \multicolumn{2}{|c|}{ Conversion vector } \\
\cline { 2 - 3 } & $\boldsymbol{r}_{\boldsymbol{I}}$ & $\boldsymbol{r}_{\boldsymbol{2}}$ \\
\hline$A_{1}$ & 0.204 & 0.085 \\
\hline$A_{2}$ & 0.244 & 0.017 \\
\hline$A_{3}$ & 0.534 & 0.254 \\
\hline$A_{4}$ & 0.238 & 0.339 \\
\hline$A_{5}$ & 0.233 & 0.169 \\
\hline$A_{6}$ & 0.367 & 0.034 \\
\hline$A_{7}$ & 0.260 & 0.509 \\
\hline$A_{8}$ & 0.298 & 0.678 \\
\hline$A_{9}$ & 0.460 & 0.254 \\
\hline
\end{tabular}

TABLE VI. ENTROPY WEIGHT SET

\begin{tabular}{|c|c|}
\hline $\boldsymbol{e}_{\boldsymbol{1}}$ & $\boldsymbol{e}_{\boldsymbol{2}}$ \\
\hline 2.6831 & 5.1092 \\
\hline $\boldsymbol{w}_{\boldsymbol{1}}$ & $\boldsymbol{w}_{\boldsymbol{2}}$ \\
\hline 0.2906 & 0.7094 \\
\hline
\end{tabular}

Step 4: The weighted normalized rating is calculated by (7), using an entropy weight set. The result is shown in Table VII.

Step 5: The best and the worst solutions are determined using (5) and (6). The result is shown in Table VIII.

Step 6: PIS and NIS are calculated among the alternatives by (7) and (8).

Step 7: PIS $\left(C_{j}^{*}\right)$ can be derived according to (9).

Step 8: PIS $\left(C_{j}^{*}\right)$ is arranged and the best and the worst alternatives are selected (Table IX).

TABLE VII. ENTROPY WEIGHTED NORMALIZED RATING

\begin{tabular}{|c|c|c|}
\hline Alternative & $\boldsymbol{v}_{\boldsymbol{I}}$ & $\boldsymbol{v}_{\boldsymbol{2}}$ \\
\hline$A_{1}$ & 0.0591 & 0.0602 \\
\hline$A_{2}$ & 0.0709 & 0.0120 \\
\hline$A_{3}$ & 0.1552 & 0.1804 \\
\hline$A_{4}$ & 0.0690 & 0.2406 \\
\hline$A_{5}$ & 0.0676 & 0.1202 \\
\hline$A_{6}$ & 0.1066 & 0.0241 \\
\hline$A_{7}$ & 0.0755 & 0.3608 \\
\hline$A_{8}$ & 0.0867 & 0.4810 \\
\hline$A_{9}$ & 0.1338 & 0.1804 \\
\hline
\end{tabular}

TABLE VIII. BEST AND WORST SOLUTIONS

\begin{tabular}{|c|c|c|}
\hline & $\boldsymbol{R}_{\boldsymbol{a}}$ & MRR \\
\hline $\boldsymbol{A}^{+}$ & 0.059148495 & 0.011989059 \\
\hline $\boldsymbol{A}^{-}$ & 0.155203335 & 0.481005487 \\
\hline
\end{tabular}

TABLE IX. THE RANKING OF THE ALTERNATIVES

\begin{tabular}{|c|c|c|c|c|c|c|}
\hline Alternative & $\boldsymbol{v}_{\boldsymbol{1}}$ & $\boldsymbol{v}_{\boldsymbol{2}}$ & $\boldsymbol{S}^{+}$ & $\boldsymbol{S}^{\boldsymbol{*}}$ & $\boldsymbol{C}^{\boldsymbol{*}}$ & Ranking \\
\hline$A_{1}$ & 0.0591 & 0.0602 & 0.4317 & 0.0482 & 0.1004 & 7 \\
\hline$A_{2}$ & 0.0709 & 0.0120 & 0.4765 & 0.0117 & 0.0240 & 9 \\
\hline$A_{3}$ & 0.1552 & 0.1804 & 0.3006 & 0.1939 & 0.3921 & 4 \\
\hline$A_{4}$ & 0.0690 & 0.2406 & 0.2554 & 0.2288 & 0.4725 & 3 \\
\hline$A_{5}$ & 0.0676 & 0.1202 & 0.3713 & 0.1086 & 0.2263 & 6 \\
\hline$A_{6}$ & 0.1066 & 0.0241 & 0.4595 & 0.0490 & 0.0964 & 8 \\
\hline$A_{7}$ & 0.0755 & 0.3608 & 0.1442 & 0.3492 & 0.7077 & 2 \\
\hline$A_{8}$ & 0.0867 & 0.4810 & 0.0686 & 0.4698 & 0.8727 & 1 \\
\hline$A_{9}$ & 0.1338 & 0.1804 & 0.3014 & 0.1842 & 0.3794 & 5 \\
\hline
\end{tabular}

According to Table IX, the $A_{8}$ is the best alternative, with $R_{a}$ and MRR values of $0.41166 \mu \mathrm{m}$ and 43.33 respectively. The worst is $A_{2}$ with $R_{a}$ value at $0.336667 \mu \mathrm{m}$. The production rate accounted for was $1.08 \mathrm{~cm}^{3} / \mathrm{min}$. The value of surface quality in $A_{8}$ alternative is worse than in $A_{2}$, but its MRR is about 40 times higher.

\section{ANOVA ANALYSIS}

In Table $\mathrm{X}$ we can see the SNR versus $V_{c}, f_{z}, a_{p}$ (smaller is better). Table $X$ and Figure 3 illustrate that in the milling of the titanium alloy Ti-6Al-4V under MQL conditions, the feed rate value impacts significantly on surface roughness, followed by the effect of cutting speed $V_{c}$. On the other hand, the influence of depth of cut $a_{p}$ on the surface quality is fuzzy.

TABLE $X$. RESPONSE TABLE FOR SIGNAL TO NOISE RATIOS

\begin{tabular}{|c|c|c|c|}
\hline Level & $\boldsymbol{V}_{\boldsymbol{c}}$ & $\boldsymbol{f}_{\boldsymbol{z}}$ & $\boldsymbol{a}_{\boldsymbol{p}}$ \\
\hline 1 & 7.710 & 9.872 & 8.214 \\
\hline 2 & 8.483 & 9.009 & 7.691 \\
\hline 3 & 6.850 & 4.163 & 7.138 \\
\hline Delta & 1.633 & 5.709 & 1.076 \\
\hline Rank & 2 & 1 & 3 \\
\hline
\end{tabular}

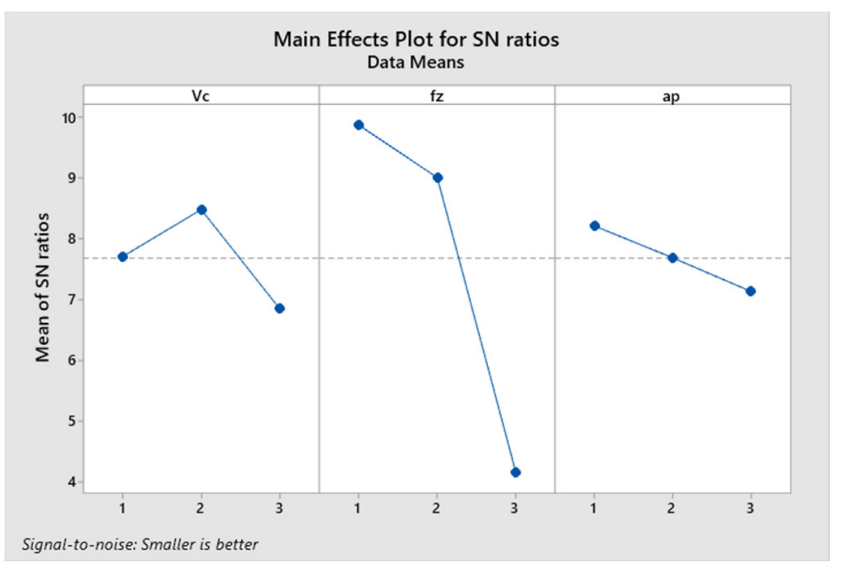

Fig. 3. Main effects signal to noise ratios.

TABLE XI. SOLUTION RANKING BY ANOVA ANALYSIS

\begin{tabular}{|c|c|c|c|c|c|c|}
\hline Solution & $\boldsymbol{V}_{\boldsymbol{c}}$ & $\boldsymbol{f}_{\boldsymbol{z}}$ & $\boldsymbol{a}_{\boldsymbol{p}}$ & MRR fit & $\boldsymbol{R}_{\boldsymbol{a}}$ fit & $\begin{array}{c}\text { Composite } \\
\text { desirability }\end{array}$ \\
\hline 1 & 120 & 0.03 & 0.6 & 44.1492 & 0.369511 & 0.897796 \\
\hline 2 & 120 & 0.03 & 0.2 & 33.2325 & 0.334549 & 0.819577 \\
\hline 3 & 120 & 0.065 & 0.6 & 36.6512 & 0.411079 & 0.775842 \\
\hline 4 & 120 & 0.03 & 0.4 & 30.7508 & 0.351432 & 0.770634 \\
\hline 5 & 120 & 0.065 & 0.2 & 26.7734 & 0.370215 & 0.699454 \\
\hline 6 & 120 & 0.065 & 0.4 & 24.5508 & 0.389908 & 0.650340 \\
\hline 7 & 90 & 0.03 & 0.6 & 18.8877 & 0.312368 & 0.626507 \\
\hline 8 & 90 & 0.065 & 0.6 & 14.1041 & 0.344462 & 0.515162 \\
\hline 9 & 60 & 0.03 & 0.6 & 13.4869 & 0.329394 & 0.512360 \\
\hline
\end{tabular}

TABLE XII. ERROR OF CALCULATED AND ANOVA RESULTS

\begin{tabular}{|c|c|c|c|}
\hline & Calculated values & Predicted values & Error \\
\hline MRR & 43.330 & 44.1492 & $1.856 \%$ \\
\hline $\boldsymbol{R}_{\boldsymbol{a}}$ & 0.4116667 & 0.369511 & $10.24 \%$ \\
\hline
\end{tabular}

Multi-response optimization is performed by the ANOVA tool in MiniTab, and the result is presented in Figure 4. The 
ANOVA analysis gives similar results. Its best solution is at $0.32 \mu \mathrm{m}$ of surface roughness and $34.3078 \mathrm{~cm}^{3} / \mathrm{min}$ MRR, while the predicted results are 0.41 and 43.33 respectively (Table XIII).

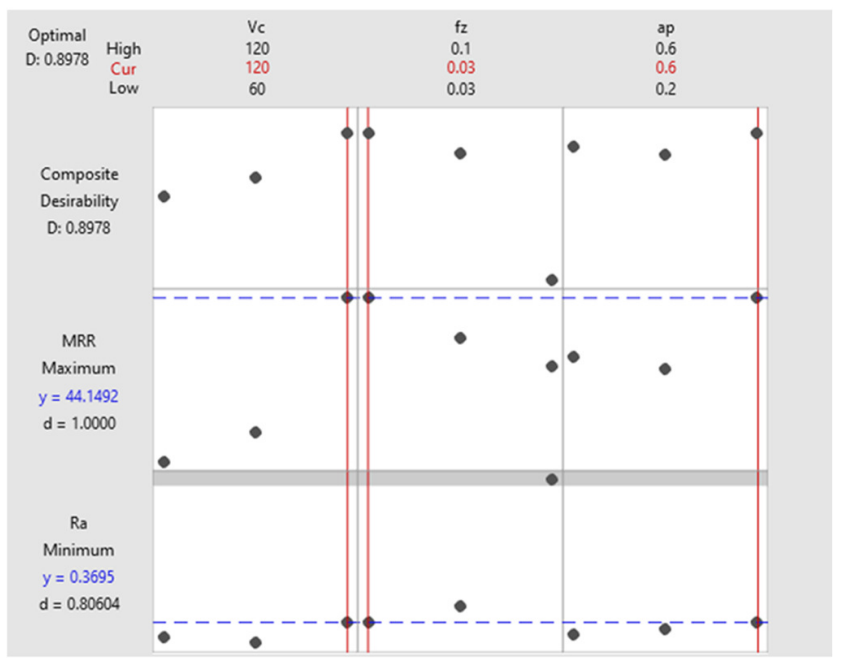

Fig. 4. Multiple response optimization analysis results.

TABLE XIII. ANOVA AND TOPSIS MULTI OPTIMIZATION RESULTS COMPARISON

\begin{tabular}{|c|c|c|}
\hline & \multicolumn{2}{|c|}{ Best solution set determined by } \\
\cline { 2 - 3 } & TOPSIS & ANOVA \\
\hline $\boldsymbol{V}_{c}(\mathbf{m} / \mathbf{m})$ & 120 & 120 \\
\hline $\boldsymbol{f}_{\boldsymbol{z}}(\mathbf{m m} / \mathbf{t o o t h})$ & 0.065 & 0.03 \\
\hline $\boldsymbol{a}_{p}(\mathbf{m m})$ & 0.2 & 0.6 \\
\hline $\boldsymbol{R}_{\boldsymbol{a}}(\boldsymbol{\mu m})$ & 0.41 & 0.32 \\
\hline MRR $\left(\mathbf{c m}^{\mathbf{3}} / \mathbf{m i n}\right)$ & 43.33 & 34.30 \\
\hline
\end{tabular}

\section{DISCUSSION}

The results in Table IX confirm that TOPSIS is the right tool for multiple responses in milling Ti-6Al-4V. Multiresponse optimization analysis with TOPSIS and ANOVA tools in Minitab showed relatively similar best choice results. TOPSIS shows the $A_{8}$ alternative at $V_{c}=120 \mathrm{~m} / \mathrm{min}$, $f_{z}=0.065 \mathrm{~mm} /$ tooth and $a_{p}=0.2$ as the best parameters set, where $R_{a}=0.412 \mu \mathrm{m}$ and production rate accounts for $43.330 \mathrm{~cm}^{3} / \mathrm{min}$. Meanwhile, for ANOVA analysis, the most optimal choice is $R_{a}=0.36 \mu \mathrm{m}, \mathrm{MRR}=44.1492 \mathrm{~cm}^{3} / \mathrm{min}$. The analytical results in Table $\mathrm{X}$ show that the difference between these two methods is $1.856 \%$ in MRR and $10.24 \%$ in roughness.

Noticeable, TOPSIS helps selecting the best one out of 9 experimental options only, which means that the set of parameters of cutting mode is one of the implemented parameter sets, whereas the ANOVA allows the prediction of the best cutting parameters based on the experimental data. In this case, the optimal set of parameters is predicted to be $\left(V_{c}=120 \mathrm{~m} / \mathrm{min}, f_{z}=0.03 \mathrm{~mm} /\right.$ tooth, and $\left.a_{p}=0.6 \mathrm{~mm}\right)$. This predicted parameter set does not coincide with any implemented parameters. This study shows that combining TOPSIS and ANOVA analysis could be applied to approve the multiple optimization of the cutting process.

\section{CONCLUSION}

The current work aimed at optimizing the cutting parameters in the milling of Ti-6Al-4V under MQL condictions. TOPSIS method and ANOVA analyis were performed and the following findings of this research should be considered:

- MQL with vegetable oil is successfully applied in the face milling of Ti-6Al-4V.

- The impact of feed rate on surface roughness is significant. Increasing feed rate or cutting speed lead to rising production rate (MRR) but reduce the quality of surface roughness.

- The best solution chosen by TOPIS is $\left(V_{c}=120 \mathrm{~m} / \mathrm{min}\right.$, $f_{z}=0.065 \mathrm{~mm} /$ tooth, and $a_{p}=0.2 \mathrm{~mm}$ ), where the surface roughness and the material removal rate are $0.41 \mu \mathrm{m}$ and $44.1492 \mathrm{~cm}^{3} / \mathrm{min}$ respectively.

- The best solution predicted by MiniTab is $\left(V_{c}=120 \mathrm{~m} / \mathrm{min}\right.$, $f_{z}=0.03 \mathrm{~mm} /$ tooth, and $\left.a_{p}=0.6 \mathrm{~mm}\right)$, where the surface roughness is $0.32 \mu \mathrm{m}$ and the material removal rate is $34.4 \mathrm{~cm}^{3} / \mathrm{min}$.

- The TOPSIS model can be applied to find the best parameters set in the milling of Ti-6Al-4V. This model can be used in different machining processes or materials.

- ANOVA analysis by software can be used to predict and find the best alternative of the milling process based on the regression model. The parameter set predicted by ANOVA analysis does not coincide with any implemented parameters.

\section{ACKNOWLEGEMENT}

The authors appreciate the assistance from the Hanoi University of Industry for the support in the research process.

\section{REFERENCES}

[1] M. A. Elfghi and M. Gunay, "Mechanical Properties of Powder Metallugry (Ti-6Al-4V) with Hot Isostatic Pressing," Engineering, Technology \& Applied Science Research, vol. 10, no. 3, pp. 5637-5642, Jun. 2020, https://doi.org/10.48084/etasr.3522.

[2] M. Jamil et al., "Sustainable milling of Ti-6Al-4V: A trade-off between energy efficiency, carbon emissions and machining characteristics under MQL and cryogenic environment," Journal of Cleaner Production, vol. 281, Jan. 2021, Art. no. 125374, https://doi.org/10.1016/j.jclepro.2020. 125374.

[3] D. Yang, Z. Liu, X. Xiao, and F. Xie, "The Effects of Machininginduced Surface Topography on Fatigue Performance of Titanium Alloy Ti-6Al-4V," Procedia CIRP, vol. 71, pp. 27-30, Jan. 2018, https://doi.org/10.1016/j.procir.2018.05.015.

[4] M. I. Sadik and S. Isakson, "The role of PVD coating and coolant nature in wear development and tool performance in cryogenic and wet milling of Ti-6Al-4V," Wear, vol. 386-387, pp. 204-210, Sep. 2017, https://doi.org/10.1016/j.wear.2017.02.049.

[5] A. Mamedov and I. Lazoglu, "Thermal analysis of micro milling titanium alloy Ti-6Al-4V," Journal of Materials Processing Technology, vol. 229, pp. 659-667, Mar. 2016, https://doi.org/ 10.1016/j.jmatprotec.2015.10.019.

[6] M. J. Bermingham, W. M. Sim, D. Kent, S. Gardiner, and M. S. Dargusch, "Tool life and wear mechanisms in laser assisted milling Ti6Al-4V," Wear, vol. 322-323, pp. 151-163, Jan. 2015, https://doi.org/ 10.1016/j.wear.2014.11.001. 
[7] N. E. Karkalos, N. I. Galanis, and A. P. Markopoulos, "Surface roughness prediction for the milling of $\mathrm{Ti}-6 \mathrm{Al}-4 \mathrm{~V}$ ELI alloy with the use of statistical and soft computing techniques," Measurement, vol. 90, pp. 25-35, Aug. 2016, https://doi.org/10.1016/j.measurement.2016. 04.039 .

[8] A. Dadgari, D. Huo, and D. Swailes, "Investigation on tool wear and tool life prediction in micro-milling of Ti-6Al-4V," Nanotechnology and Precision Engineering, vol. 1, no. 4, pp. 218-225, Dec. 2018, https://doi.org/10.1016/j.npe.2018.12.005.

[9] A. Shokrani, V. Dhokia, and S. T. Newman, "Investigation of the effects of cryogenic machining on surface integrity in $\mathrm{CNC}$ end milling of $\mathrm{Ti}-$ 6Al-4V titanium alloy," Journal of Manufacturing Processes, vol. 21, pp. 172-179, Jan. 2016, https://doi.org/10.1016/j.jmapro.2015.12.002.

[10] M. I. Sadik, S. Isakson, A. Malakizadi, and L. Nyborg, "Influence of Coolant Flow Rate on Tool Life and Wear Development in Cryogenic and Wet Milling of Ti-6Al-4V," Procedia CIRP, vol. 46, pp. 91-94, Jan. 2016, https://doi.org/10.1016/j.procir.2016.02.014.

[11] N. R. Dhar, M. Kamruzzaman, and M. Ahmed, "Effect of minimum quantity lubrication (MQL) on tool wear and surface roughness in turning AISI-4340 steel," Journal of Materials Processing Technology, vol. 172, no. 2, pp. 299-304, Feb. 2006, https://doi.org/10.1016/ j.jmatprotec.2005.09.022.

[12] K. N. Ronoha, N. W. Karuri, F. M. Mwema, H. T. Ngethac, S. A. Akinlabi, and E. T. Akinlabi, "Evaluation of the Surface Roughness of Ti-6Al-4V for Surface Grinding under Different Cooling Methods Using Conventional and Vegetable Oil-based Cutting Fluids," Tribology in Industry, vol. 41, no. 4, pp. 634-647, Sep. 2019.

[13] N. Benmoussa, A. Elyamami, K. Mansouri, M. Qbadou, and E. Illoussamen, "A Multi-Criteria Decision Making Approach for Enhancing University Accreditation Process," Engineering, Technology \& Applied Science Research, vol. 9, no. 1, pp. 3726-3733, Feb. 2019, https://doi.org/10.48084/etasr.2352.

[14] A. K. Parida and B. C. Routara, "Multiresponse Optimization of Process Parameters in Turning of GFRP Using TOPSIS Method," International Scholarly Research Notices, vol. 2014, 2014, Art. no. 905828, https://doi.org/10.1155/2014/905828.

[15] F. Jafarian and H. Samarikhalaj, "Experimental Investigation and Optimizing Geometrical Characteristics and Surface Quality in Drilling of AISI H13 Steel," Journal of Applied and Computational Mechanics, vol. 6, no. 2, pp. 332-343, Apr. 2020, https://doi.org/10.22055/ jacm.2019.29070.1552.

[16] G. Maheedhara Reddy, V. Diwakar Reddy, B. Satheesh Kumar, and J. Shyamsunder, "Experimental Investigation on Radial Ball Bearing Parameters Using Taguchi Method," Journal of Applied and Computational Mechanics, vol. 4, no. 1, pp. 69-74, Jan. 2018, https://doi.org/10.22055/jacm.2017.22072.1124.

[17] M. Hassanzadeh and S. E. Moussavi Torshizi, "Multi-objective optimization of shot-peening parameters using design of experiments and finite element simulation: a statistical model," Journal of Applied and Computational Mechanics, May 2020, https://doi.org/10.22055/ jacm.2020.33102.2152.

[18] K. Krishnaprasad, C. S. Sumesh, and A. Ramesh, "Numerical Modeling and Multi Objective Optimization of Face Milling of AISI 304 Steel," Journal of Applied and Computational Mechanics, vol. 5, no. 4, pp. 749-762, Jun. 2019, https://doi.org/10.22055/jacm.2019.27528.1414.

[19] H. Zheng, D. Si, W. Wang, and R. Wang, "Quantitative Entropy Weight TOPSIS Evaluation of Sustainable Chinese Wind Power Developments," Mathematical Problems in Engineering, vol. 2018, Sep. 2018, Art. no. 6965439, https://doi.org/10.1155/2018/6965439.

[20] J. Huang, "Combining entropy weight and TOPSIS method for information system selection," in IEEE Conference on Cybernetics and Intelligent Systems, Chengdu, China, Sep. 2008, pp. 1281-1284, https://doi.org/10.1109/ICCIS.2008.4670971.

[21] R. V. Rao, Decision Making in the Manufacturing Environment: Using Graph Theory and Fuzzy Multiple Attribute Decision Making Methods. London, UK: Springer, 2007.

[22] J.-C. Liu, "Stationarity for a Markov-switching Box-Cox transformed threshold GARCH process," Statistics \& Probability Letters, vol. 77, no. 13, pp. 1428-1438, Jul. 2007, https://doi.org/10.1016/j.spl.2007.02.009.
[23] S. Y. Hwang and I. V. Basawa, "Stationarity and moment structure for Box-Cox transformed threshold GARCH $(1,1)$ processes," Statistics \& Probability Letters, vol. 68, no. 3, pp. 209-220, Jul. 2004, https://doi.org/10.1016/j.spl.2003.08.016.

[24] B. Singaravel, D. P. Shankar, and L. Prasanna, "Application of MCDM Method for the Selection of Optimum Process Parameters in Turning Process," Materials Today: Proceedings, vol. 5, no. 5, Part 2, pp. 13464-13471, Jan. 2018, https://doi.org/10.1016/j.matpr.2018.02.341.

[25] R. V. Rao, Decision Making in the Manufacturing Environment: Using Graph Theory and Fuzzy Multiple Attribute Decision Making Methods. London, UK: Springer, 2007.

[26] G.-H. Tzeng and J.-J. Huang, Fuzzy Multiple Objective Decision Making, 1st edition. Florida, United States: CRC Press, 2013.

[27] J. Xu and X. Zhou, Fuzzy-Like Multiple Objective Decision Making, 2011 th edition. Berlin, Germany: Springer, 2011.

[28] G.-H. Tzeng and J.-J. Huang, Multiple Attribute Decision Making: Methods and Applications. Florida, USA: CRC Press, 2011.

\section{AUTHOR PROFILES}

Van Canh Nguyen is a lecturer at the Department of Manufacturing Technology, Faculty of Mechanical Engineering, Hanoi University of Industry. $\mathrm{He}$ is a $\mathrm{PhD}$ candidate, and his research work focuses on the multiple optimization of metal cutting process under minimum quantity lubricant.

Thuy Duong Nguyen is a $\mathrm{PhD}$ in the Department of Machine Tool and Tribology, School of Mechanical Engineering, Hanoi University of Science and Technology. Her research focuses on the effects of friction and tribology on machine parts.

Dung Hoang Tien is an associate professor at the Department of Manufacturing Technology, Faculty of Mechanical Engineering, Hanoi University of Industry. His research work focuses on multi-optimization, addaptive machining, and micro-machining. 